\title{
Electronic Resources: The Ohio State University EESEE Project
}

PETRA L. GRAHAM $\dagger$

pgraham@maths.newcastle.edu.au Statistics, School of Mathematical and Physical Sciences, University of Newcastle, Australia

WILLIAM I. NOTZ

win@stat.ohio-state.edu

Department of Statistics, The Ohio State University, USA

DENNIS K. PEARL

Department of Statistics, The Ohio State University, USA

dkp@stat.ohio-state.edu

ELIZABETH A. STASNY

eas@stat.ohio-state.edu

Department of Statistics, The Ohio State University, USA

Abstract. Electronic resources aid in the teaching and learning of statistics by providing data that may be used interactively by teachers and students. By interacting with the data students are encouraged to discover knowledge and thereby gain a deeper understanding of statistical concepts. The Electronic Encyclopedia of Statistical Examples and Exercises (EESEE) is an electronic resource that includes over 80 'real-world' examples about the uses and abuses of statistics. These examples are drawn from published and printed media and the diverse range of subject-matter areas make it suitable for use in any statistics course.

Keywords: education resources, multimedia, statistics education, teaching and learning statistics

\section{Introduction}

Modern teaching methods encourage students to discover knowledge [10] and learn concepts by working on real problems. Known as constructivism in educational theory, this method allows the student to construct their own understanding of a problem (see [9] and [3] for more detailed descriptions). Literature agrees that learning in this way promotes deeper understanding and critical thinking ([5], [4]).

Real-world examples are also an important pedagogical tool because they not only help to illustrate the practical use of statistics [5] but are also

$\dagger$ Requests for reprints should be sent to Petra L. Graham, Statistics, School of Mathematical and Physical Sciences, University of Newcastle, Australia. 
usually more interesting to students. Difficulties arise however, because instructors often lack access to a large number of real world examples that demonstrate different statistical concepts from subject matter areas to which their students will relate [2]. Furthermore, finding suitable data "can be a daunting and time-consuming task" [11]. Moreover, the mode of delivery of such examples is often a hurdle: the instructor may lack the experience or time to develop the problem sufficiently well in a face-to-face situation and continued use of experts to present real-world problems may be costly and/or impractical.

Electronic resources may overcome these problems in that they involve an initial set-up cost but then allow for more complete development of a real-world example that can be accessed by learners in a flexible manner at any time. A number of such resources are currently available. For example, DASL (the Data and Story Library) [11] contains a wide variety of data sets and stories that are indexed by subject matter area and statistical method. The Rice Virtual Laboratory in Statistics [5] provides some excellent interactive simulations to demonstrate statistical concepts. It also includes an electronic textbook and a few case studies. Both of these are available online. See references [1], [2], [4], [5] and [11] for a description of some other useful electronic resources.

The Electronic Encyclopedia of Statistical Examples and Exercises, or EESEE, is a hands-on learning multimedia program containing many interesting current and historical real world examples from a wide variety of topics including, business, medicine and sports. EESEE is a sister project of DASL but presents each story in a common format that includes, among other features, pictures, questions, projects and downloadable data sets.

The following two sections provide an overview of the EESEE program including a brief graphical tour of some features of EESEE.

\section{The EESEE Program}

The Electronic Encyclopedia of Statistical Examples and Exercises is the product of a National Science Foundation grant to faculty at The Ohio State University (OSU) and Cornell University. W.H. Freeman and Company currently support the continued development of EESEE at OSU. EESEE is available on compact disc (CD) and is included with two introductory textbooks published by W.H. Freeman ([6], [7]). For those adopting alternative textbooks, EESEE is available from W.H. Freeman as a stand-alone CD [8].

EESEE contains over 80 examples (known as 'stories') obtained from popular press and journals. Each story contains at least one picture and 
may also contain maps and videos. Most stories contain a data set, which may be downloaded in one of four commonly used formats (Minitab, Data Desk, JMP and text) and most stories also contain useful project ideas.

Questions accompany all stories and are available in one or all of three different user levels. The levels, which are based on mathematical ability, are:

Basic - this level avoids the use of formulas and mathematical derivation.

Semi-technical - this level assumes knowledge of high-school algebra.

Calculus-based - this level assumes familiarity with first year college calculus.

An instructor's CD is also available containing model solutions to each of the questions.

EESEE is indexed to several W.H. Freeman textbooks ([6], [7], [12]), and by using EESEE as a supplement to one of these texts, instructors may easily choose appropriate stories and questions for students to work through that demonstrate and reinforce the concepts being taught. A description of the indexing is given in the following section.

\section{Using EESEE}

At present, the version of EESEE available on CD is a point and click multimedia program written in Authorware. The program may be used on both Macintoshes and PC's and will soon be available in an HTML version on the W.H. Freeman website (http://www.whfreeman.com/eesee). In this section the Authorware version of EESEE is presented. The HTML version retains much of the functionality of the Authorware version but has a slightly different appearance.

On starting EESEE a bookshelf appears (see Figure 1) containing the topic index. Choosing stories from this index may stimulate the interest of students according to their background, for example psychology students may be more interested in the human behavior stories. Clicking on one of the topic 'books' leads the user to the titles of stories relevant to that topic.

Figure 2 shows the stories available in the Human Behavior topic book. Clicking on a story title takes the user to that story. Navigation through EESEE is similar to using a web browser, which means that most people will find using EESEE very straightforward. For less experienced users, the 'Help' button (on the left-hand side of the EESEE screen) will lead 


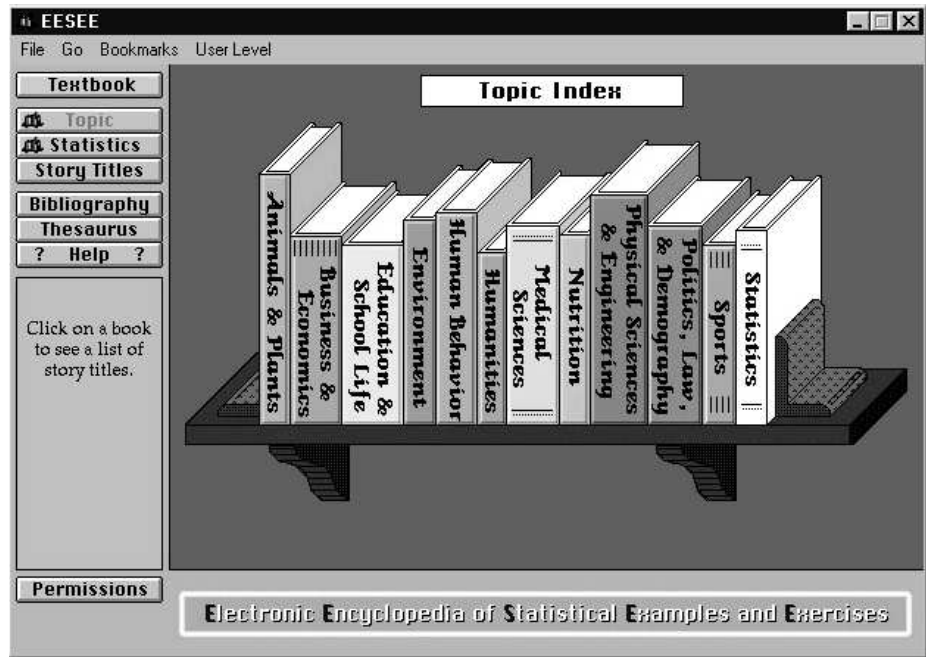

Figure 1. Topic Index (Initial page of EESEE).

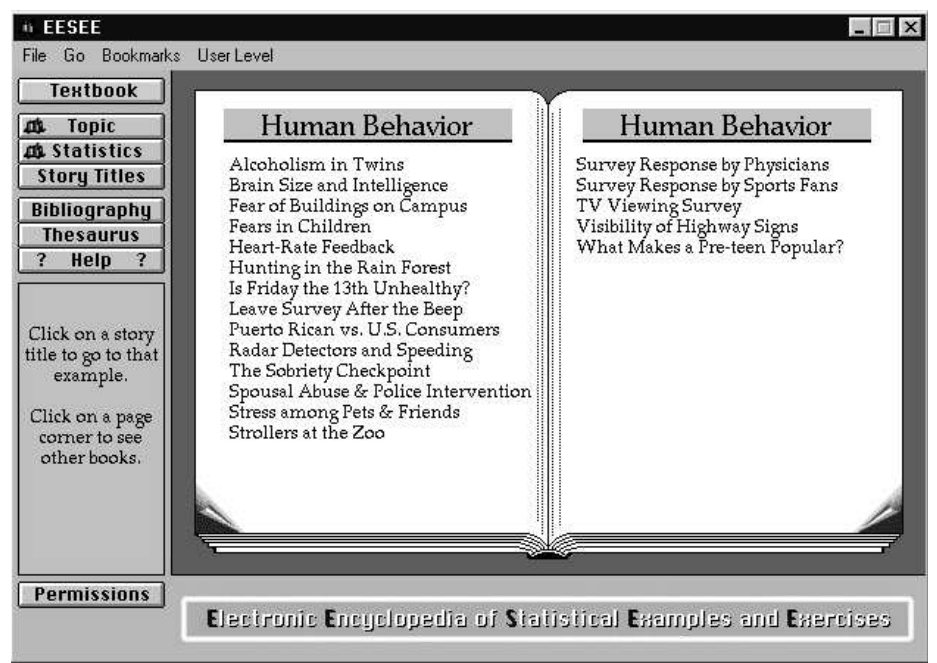

Figure 2. Human Behavior story titles. 
to a detailed explanation of all features from simple navigation to more advanced items.

It is also possible to choose stories according to statistical topics. Clicking on the 'Statistics' button on the left hand side of the EESEE screen will lead to another bookshelf containing statistical 'books' (see Figure 3). Using the statistics index may help educators to choose stories that are appropriate to the material being taught. When the user enters a story from this index, questions associated with the statistical topic will be highlighted with red square brackets to make them obvious. In the bottom left-hand corner of Figure 4, square brackets surround question 2 and the statistical topic it is linked to (Compute/Interpret Std. Deviation) may be seen below the questions.

Note also in Figure 4 that some of the question numbers are pale grey whereas others are darker. This difference occurs because the pale questions are unavailable to the current user level. The user level may be changed by clicking on the 'User Level' drop down menu at the top of the screen and changing the level appropriately. At the highest user level all of the questions are available.

Other useful features of EESEE include definitions of certain words within stories, a thesaurus, and instructor's comments that provide tips on various matters of interest. Each story has a synopsis (see the button in the bottom left-hand corner of Figure 4) containing a brief description of the main issue, the statistical focus of the questions and whether or not the story has a downloadable data set, a map or other items. The synopses may be scrolled through by clicking on the 'Story Titles' button and then holding down the Alt key (on a PC) and clicking on a story title.

Finally, as discussed earlier, another important feature of EESEE is it's indexing to several introductory statistical textbooks ([6], [7], [12]). Clicking on the 'Textbook' button at the top left-hand corner of the EESEE screen will lead to the default textbook with a list of its chapters. Clicking on a chapter reveals the sections within that chapter and the EESEE stories related to that section. Figure 5 shows the first chapter of the Introduction to the Practice of Statistics [6] textbook and the EESEE stories related to section 1.1 (Displaying

\section{Conclusion}

Electronic resources, such as EESEE, are a useful source for real-world examples that may be used by instructors to aid in the teaching and learning of statistics. By working interactively on real problems, students will gain a deeper understanding of statistical concepts and develop critical thinking 


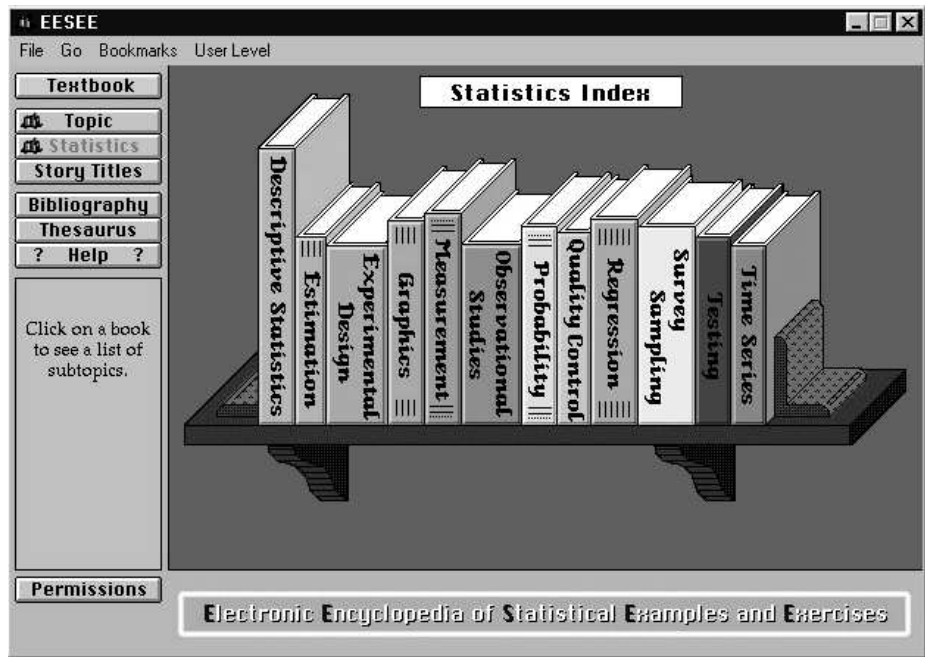

Figure 3. Statistics Index.

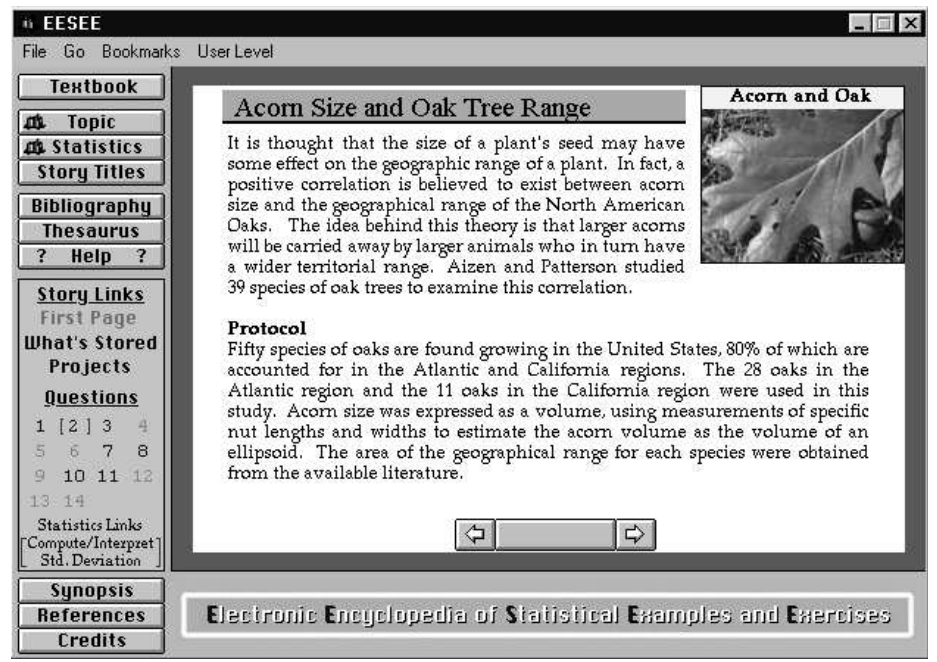

Figure 4. A story showing the statistical index link to question 2. 


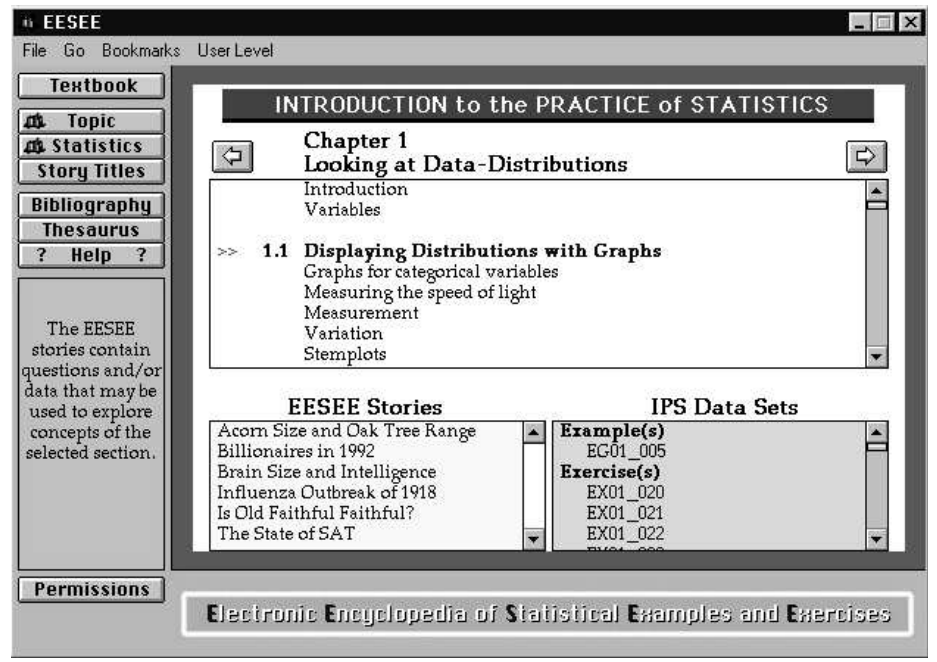

Figure 5. EESEE information for the first chapter from Introduction to the Practice of Statistics.

skills. Furthermore by using relevant examples the students will develop an appreciation for the practical use of statistics and will also find it more interesting.

EESEE provides examples that are suitable to a diverse range of undergraduate majors from a diverse range of mathematical backgrounds. It is easy to use and contains many practical features. By including a large number of interesting stories in a wide variety of subject-matter areas, EESEE is the ideal supplement to any introductory statistical course.

\section{Acknowledgments}

The authors would like to thank Professor Kerrie Mengersen for her valuable comments and suggestions.

Work on EESEE was supported by NSF grants USE-915625 (1992-1995) and DUE-9555073 (1995-1998) and work on this paper was supported by ARC SPIRT grant C10024120. 


\section{References}

1. B.J. Becker. A look at the literature (and other resources) on teaching statistics. Journal of Educational and Behavioral Statistics, 21(1):71-90, 1996.

2. A. Bowman, W.H. Gilmour, G. Constable, N. Davies, S.G. Gilmour, and E.J. Redfern. Computer-based learning in statistics: a problem solving approach. The Statistician, 47(2):349-364, 1998.

3. L. Burton. Implications of constructivism for achievement in mathematics. In J.A. Malone and P.C.S. Taylor (Eds.), Constructivist Interpretations of Teaching and Learning Mathematics. National Key Centre for Teaching and Research in School Science and Mathematics, Curtin University of Technology, Perth, Western Australia, pp. 7-14, 1993.

4. P. Cabilio and P.J. Farrell. A computer-based lab supplement to courses in introductory statistics. The American Statistician, 55(3):228-232, 2001.

5. D.M. Lane and D.W. Scott. Simulations, case studies, and an online text: a webbased resource for teaching statistics. Metrika, 51:67-90, 2000.

6. D.S. Moore and G.P. McCabe. Introduction to the Practice of Statistics. W.H. Freeman and Company, New York, 1999.

7. D.S. Moore. The Basic Practice of Statistics. W.H. Freeman and Company, New York, 2000.

8. W.I. Notz, D.K. Pearl and E.A. Stasny. EESEE: The Electronic Encyclopedia of Statistical Examples and Exercises. Stand-alone CD, ISBN: 0-7167-4059-1, W.H. Freeman and Company, New York, 2000.

9. D.C. Phillips. An opinionated account of the constructivist landscape. In D.C. Phillips (Ed.), Constructivism in Education. The National Society for the Study of Education, Chicago, Illinois, pp. 1-16, 2000.

10. E.R. Sowey. Teaching statistics: making it memorable. Journal of Statistics Education, 3(2), 1995.

11. P.F. Velleman, M.C. Hutcheson, M.M. Meyer and J.H. Walker. DASL, the Data and Story Library: An online resource for teaching statistics. The American Statistical Association Proceedings of the Section on Statistical Education, 45-49, 1996.

12. D. Yates, D.S. Moore and G.P. McCabe. The Practice of Statistics. W.H. Freeman and Company, New York, 1998. 


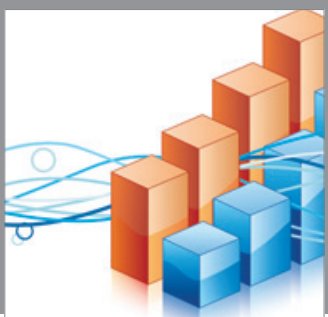

Advances in

Operations Research

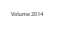

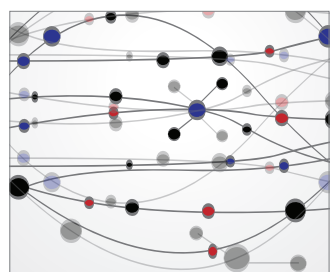

\section{The Scientific} World Journal
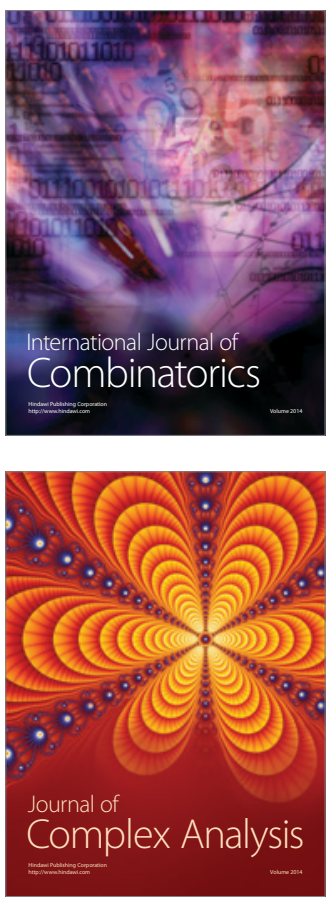

International Journal of

Mathematics and

Mathematical

Sciences
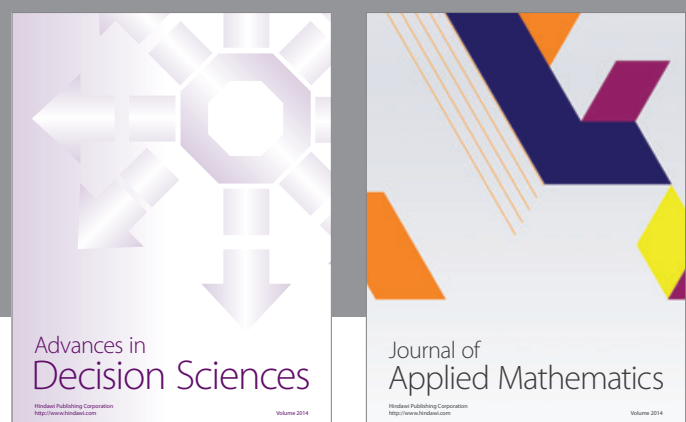

Journal of

Applied Mathematics
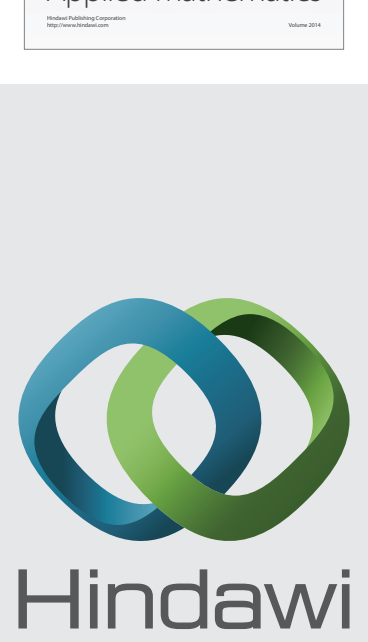

Submit your manuscripts at http://www.hindawi.com
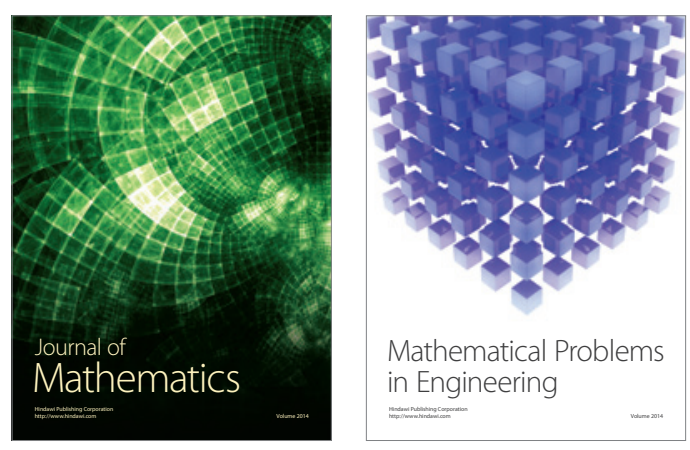

Mathematical Problems in Engineering
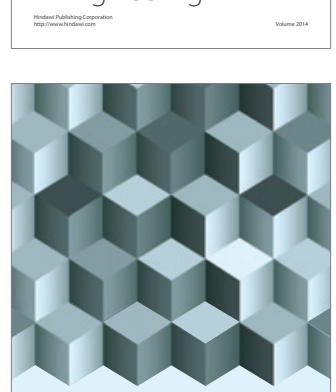

Journal of

Function Spaces
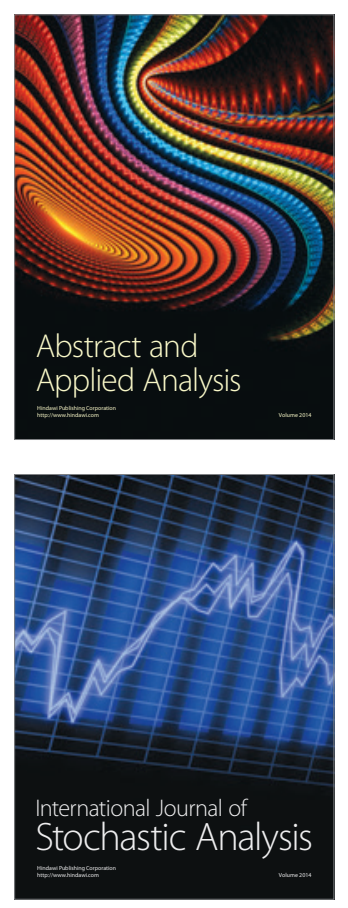

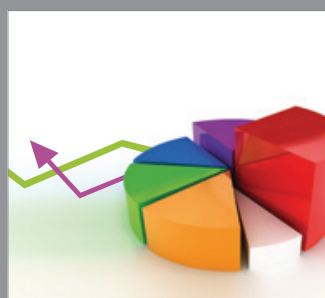

ournal of

Probability and Statistics

Promensencen
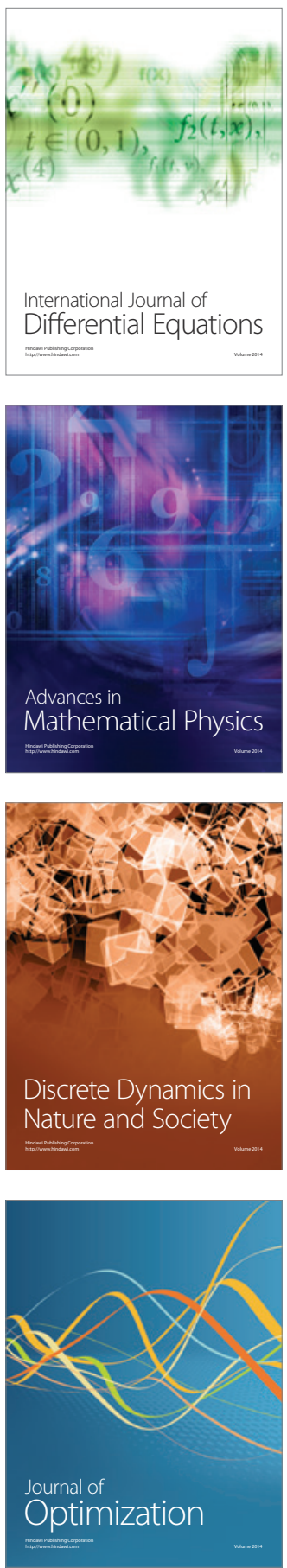